КИРСАНОВ Анатолий Иванович - доктор политических наук, заведующий кафедрой теории и практики управления, директор Института иностранных языков, современных коммуникаций и управления Московского государственного психолого-педагогического университета (123290, Россия, г. Москва, Шелепихинская наб., 2A, стр. 1; kirsanovai@mgрри.ru)

\title{
ИНФОРМАЦИОННАЯ КУЛЬТУРА - СТРАТЕГИЧЕСКИЙ РЕСУРС ПОЛИТИЧЕСКОЙ БЕЗОПАСНОСТИ ЛИЧНОСТИ В ИНФОРМАЦИОННОМ ОБЩЕСТВЕ
}

\begin{abstract}
Аннотация. В статье рассматриваются проблемы политической безопасности личности в современном информационном обществе и роль в этом вопросе информационной культуры. Автор характеризует содержание информационной культуры, особо выделяя роль образования, средств массовой информации и коммуникации и Интернета в обеспечении политической безопасности личности.

Ключевые слова: информация, информационная культура, информационное общество, политическая безопасность, личность, государство, средства массовой информации, Интернет
\end{abstract}

\begin{abstract}
$\mathrm{M}$ ногие исследователи, характеризуя вступление современного общества в информационную стадию развития, наряду с известными позитивными качественными изменениями, отмечают достаточно большое число серьезных противоречий и негативных социально-политических и политико-психологических тенденций. Но все они, как правило, упираются в факт многообразия интересов личности и общества в информационно-политической сфере и их недостаточную информационную культуру для условий информационного общества. По мнению ученых, информационная культура современного человека носит «общеинтеллектуальный и надпредметный характер» [Нурмеева 2008] и включает представление об информации как «одном из трех основополагающих понятий (наряду с веществом и энергией), на основе которых строится современная картина мира» [Пирогов 1995: 42].

Что представляет собой информационная культура личности с точки зрения освоения политической сферы жизни в информационном обществе? Автор полагает, что в первую очередь это:

- теоретические знания, обеспечивающие понимание и осмысление сущности, структуры, специфики и закономерностей функционирования политики в обществах с различными уровнями информатизации. Здесь наиболее важными являются два аспекта:

a) обязательное усвоение основных научных категорий (понятий), характеризующих функционирование политики в условиях информационного общества (информационная среда, информационные ресурсы, информационная инфраструктура, информационное мировоззрение и т.д.);

б) умение использовать полученные знания для анализа происходящих в политической сфере жизни общества политических процессов;

- новое информационное мировоззрение, позволяющее адекватно адаптироваться к политической среде информационного общества и выстраивать свою стратегию и тактику политико-информационной деятельности;

- «информационная этика», характеризующая высокий нравственный уровень политического общения в социальных сетях;

- политико-информационная грамотность, структурно включающая в себя:
\end{abstract}


a) способность выделять и формулировать политико-информационные потребности и интересы;

б) владение новыми информационными и телекоммуникационными технологиями, применяемыми в политической сфере жизни общества;

в) умение быстро и эффективно осуществлять поиск необходимой политической информации с помощью электронных поисковых систем;

г) владение всеми доступными приемами, средствами и методами обработки, хранения и передачи политической информации.

Исходя из этих представлений, политико-информационная культура личности может быть определена как синтез информационного мировоззрения, специальных знаний и умений, обеспечивающих относительно полное удовлетворение политико-информационных потребностей личности на базе новых, сочетаемых с традиционными информационных технологий.

Автор делает некоторое допущение и предлагает новое информационное мировоззрение (иногда его называют постмодернистским - для выделения специфики его функционирования в политической сфере жизни современного информационного общества) именовать «новым политико-информационным мировоззрением». Основанием для такого выделения может служить тот факт, что это - основной компонент политико-информационной культуры, отражающий совокупность политических взглядов, идей, представлений и ценностей личности, находящих свое выражение в ее политическом мировосприятии и политическом поведении.

Наконец, еще одним аргументом в пользу такого выделения может служить и то, что в настоящее время многие исследователи проблем информационной культуры общества и личности считают, что новое информационное мировоззрение уже неотделимо от информационных и телекоммуникационных технологий - главного инструмента коммуникаций в информационном обществе. (Единственное, что должно здесь заботить специалистов-политологов, - это методологические вопросы диалектики мировоззренческих и собственно технологических компонентов политико-информационной картины мира.)

Как любое мировоззрение, политико-информационное мировоззрение следует анализировать через его разделение на «обыденное» и «теоретическое». Обыденный уровень - это эмоционально-чувственное восприятие «политикоинформационного бытия», которое не дает о нем истинного представления; теоретический же уровень базируется на научном знании - он более адекватен современным представлениям о политической жизни в обществе и благодаря научному осмыслению целостности политико-информационной картины мира способствует самопозиционированию человека в информационную эпоху. Иначе говоря, новой политической картине мира в информационном обществе соответствует и новое политико-информационное мировоззрение - адекватная политико-информационная рефлексия политических явлений и процессов, непосредственно характеризующая и индивидуальную политическую защищенность личности.

Успешность формирования нового политико-информационного мировоззрения во многом определяется личной мотивацией человека. Здесь очень важно отметить тот факт, что еще четверть века назад приобретенные в ходе профессионального образования навыки работы с информацией «работали» на человека практически всю его сознательную жизнь. В настоящее время ситуация в корне изменилась. И суть заключается не только в том, что изменилась информационная среда и инструментарий информационного взаимодействия: под их воздействием сформировались новые условия политического бытия и новые политические ценности. Новая политико-информационная 
культура является в этом плане лишь императивным условием их осознания и освоения, не гарантирующим и не обеспечивающим «раз и навсегда» политическую безопасность личности, - необходимы постоянное самосовершенствование интеллекта и профессионализма.

Одной из важнейших основ этого является образование. Научнообразовательный процесс не может только запоздало отображать сущее - он обязан осуществлять опережающее отображение будущего, которое может и должно способствовать реализации новой цивилизационной стратегии [Кирсанов 2007: 75]. Многие специалисты считают, что информационная эпоха застала врасплох всю систему образования в мире, оказавшуюся не готовой к восприятию новой информационной действительности. Среди отечественных специалистов в этой области все чаще слышны голоса, что российская система образования не только безнадежно устарела, но и не позволяет личности адаптироваться к условиям информационной эпохи: будучи ориентированной на прежнюю консервативную систему, она игнорирует все то новое, что несет с собой нарождающееся информационное общество. Иначе говоря, консервативная составляющая в современном образовании воспроизводит «человека индустриального», не способного к полноценной деятельности в обществе будущего, а его совершенствование в виде «болонизации» решает лишь незначительную часть проблем, свойственных информационной стадии развития социума. И здесь нельзя не согласиться с Э. Тоффлером, утверждающим, что «во избежание шока будущего мы должны сейчас сформировать супериндустриальную систему образования; а для этого мы должны искать свои цели и методы в будущем, а не в прошлом» [Тоффлер 2002: 432]. Только в этом случае можно будет говорить о формировании новой информационной культуры, обеспечивающей информационную, профессиональную, политическую и иные виды безопасности личности и общества.

Информационная культура (необходимый ее уровень) формирует и базис освоения научных знаний, который, в свою очередь, не успевает «переварить» всю научную информацию. Как опять же справедливо заметил Э. Тоффлер, «с началом дальнейшего ускорения развития мы можем сделать вывод о том, что знание становится все более “скоропортящимся" продуктом. Сегодняшний “факт” превращается завтра в “дезинформацию”» [Тоффлер 2002: 450].

Как этого избежать?

Разумеется, у автора нет полного и всеобъемлющего ответа на этот вопрос; он ограничивается выделением лишь некоторых направлений в его решении.

Представляется, что исключительно важную роль в этом процессе играет мотивация к самообразованию. Наша система начального, среднего и высшего образования страдает двумя пороками: во-первых, стремлением транслировать знания от учителя (преподавателя) к ученику (студенту), вместо того чтобы научить методологии их освоения и использования; во-вторых, отчуждением обучающихся от политической жизни общества, ведущим к крайне низкому уровню политической культуры и пагубно сказывающимся в перспективе на политической безопасности личности. Главным в любой системе образования является не стремление передать как можно больший объем знаний (в условиях современного информационного общества это утопия), а научение тому, как самостоятельно его добывать и использовать в соответствии с условиями профессиональной и иной, в т.ч. политической, деятельности. «Мерой знания становится такая его ценностно-качественная характеристика, как “вочеловеченность"» [Хакен 1991: 154]. Соответственно, в качестве базиса информационного образования (которое сегодня ограничивается формированием первичной компьютерной грамотности, что является лишь одним из элементов 
информационной культуры) должен быть положен принцип: не сформировать, а найти, поддержать и развить в каждой личности механизмы самореализации и саморазвития, посредством которых только и можно подготовиться к жизни в современном информационном обществе и обеспечить все виды индивидуальной безопасности.

В самом общем плане многообразие интересов личности в информационнополитической сфере характеризуется способностью каждого активно и эффективно использовать информационные ресурсы и средства массовых коммуникаций (начиная с мобильного телефона и заканчивая компьютерными сетями). В условиях информационного общества совокупность информационных потоков, окружающих каждого человека, настоятельно требует от него не только понимания закономерностей развития информационной среды, но и умения адаптироваться к ней.

Как феномен информационного общества информационная культура в политической сфере жизни общества предполагает, с одной стороны, компетентное отношение к идеологии и деятельности политической власти, с другой - сознательное участие в работе ее органов.

Одним из основных показателей такой политической активности личности является ее готовность быть избранной в те или иные органы политической власти. Разумеется, эта активность в разных регионах различна, но общая тенденция примерно одинакова: особого интереса к работе во властных политических структурах люди не проявляют. Так, согласно данным исследования «Российское поколение $Z$ », проведенного немецким фондом им. Фридриха Эберта совместно с Левада-Центром в 2019 г., более $80 \%$ молодых людей не интересуются политикой либо не имеют на этот счет определенного мнения. По-настоящему она интересна лишь $19 \%$ опрошенных россиян в возрасте от 14 до 29 лет. Это объясняется не только слабым пониманием смысла политической деятельности и непониманием того, как работает политика, но и тем, что повседневные заботы молодых людей мало связаны с тем, что они считают политикой ${ }^{1}$. Такая социально-политическая пассивность свидетельствует о том, что люди слабо информированы о сущности, общественной значимости деятельности и полномочиях органов власти, что неизбежно снижает уровень политической защищенности как личности, так и общества в целом.

Здесь есть, безусловно, и объективные причины. Сказывается значение «синдрома информационной усталости» для политической защищенности личности и общества. Нас окружает и повсюду воздействует на нас самая различная информация. Ресурсы же ее освоения весьма ограничены. Для сбора информации, особенно политической, ее упорядочения, структурирования, сортировки требуются большие временные затраты, не оправдывающие себя, поскольку, во-первых, чем больше информации, тем труднее ее найти и работать с ее большими объемами, во-вторых, собранная по принципу «возможно, в будущем пригодится», она в этом будущем становится малопригодной, поскольку около ее трети устаревает и теряет свою актуальность еще когда она собирается, структурируется и т.д., и еще пятая ее часть устаревает до того времени, пока будет востребована.

Именно поэтому информационная культура человека информационного общества настоятельно требует отфильтровки всей без исключения информации на момент контакта с ней по принципу «здесь и сейчас». Вся другая планируемая для использования через какое-то время информация должна

\footnotetext{
${ }^{1}$ Более $80 \%$ российской молодежи равнодушны к политике. Доступ: https://www.vedomosti. ru/society/articles/2020/04/29/829352-molodezhi-ravnodushni (проверено 14.03.2021).
} 
отсеиваться: в информационном обществе нет ее дефицита, и нужная информация (как раскрывающая историю проблемы, так и ее перспективы) всегда будет получена в тот момент, когда она станет актуальной. Этот обязательный элемент информационной культуры помогает избежать ряда негативных последствий «информационно-политической перегрузки», влияющей в т.ч. и на здоровье человека.

Одним из важнейших элементов формирования информационной культуры вообще и политико-информационной культуры в частности является освоение новых информационных и телекоммуникационных технологий. Встраиваясь в современную социальную среду и оперируя социальной информацией, они опосредованно превращаются в инструмент социальных трансформаций, содействуют изменениям в общественном сознании и, что немаловажно, вторгаясь в ценностную сферу личности, влияют на обеспечение собственно информационной безопасности личности в целом. Происходит это во взаимодействии с другими средствами массовой информации и коммуникации (СМИК) и Интернетом. Дело в том, что современная политическая картина мира воспринимается личностью через подаваемую СМИК политическую информацию с учетом тех мировоззренческих установок, потребностей, интересов и ценностей, имеющихся у личности, но - и это главное - во многом сформированных ими же. В итоге идет как бы двойное субъективное восприятие мира политического, интерпретированного, с одной стороны, этими средствами массовой информации и коммуникации, скрыто предопределяющими или, как минимум, жестко воздействующими своими заранее заготовленными шаблонами на политическое поведение личности, с другой - интерпретированного самой личностью, стремящейся к независимым оценкам [Андреева 2000; Вачнадзе 1989].

Еще более заметен след воздействия Интернета на политическое поведение, который многом первенствует в вопросах формирования информационной культуры личности, ибо он безграничен, свободен, анонимен, что всегда импонирует человеку в его неумолимом стремлении к самовыражению [Иванов 2000: 53]. Но, будучи практически неконтролируемым [Петрова 2010: 262] в своем воздействии на личность, он более эффективен в своих красиво упакованных «домашних заготовках», ориентирующих личность на принятие уже готовых решений актуальных проблем политического бытия.

Интернет наднационален, но политические коммуникации в нем зачастую не только окрашены в национальные цвета, но и содержат прямые политические оценки происходящих в мире или стране событий, приводящие личность к поддержке различных политических организаций, в т.ч. экстремистского характера, что, безусловно, исключительно важно для оценки обеспечения ее политической безопасности. Алгоритм воздействия на политическое сознание достаточно прост: в искусственно созданной (виртуальной) политикоинформационной среде осуществляется дублирование, а затем и вытеснение естественного образного ряда, окружающего личность в обычных условиях «живых» политических коммуникаций; в результате виртуальный мир политического замещает реальный политический мир. В итоге проходящие в глобальной сети процессы, с одной стороны, способствуют формированию единого политико-информационного пространства, в котором обретают новое качество политические коммуникации, с другой - могут происходить обратные процессы демассификации (в т.ч. кризис политической социализации), разрушающие сложившиеся ранее политические связи и отношения между людьми [Давыдов 2000: 3]. Как верно замечает Г.Ю. Чернов, «трансцендентально-ориентированная картина мира, самосовершенствование, “вопрошание” о смыс- 
лах бытия не могут рождаться спонтанно в обществе массовизирующих манипуляций, являются в нем не правилами, а скорее исключениями. Массовый же человек именно “плывет по течению" (согласно Х. Ортеге-и-Гассету), живет не творческой, а преимущественно миметической жизнью и потому (зачастую с радостью и энтузиазмом) оказывается “опутанным" этим “просто дающим себя бытием вещей”» [Чернов 2011].

Культурные ценности, свободно курсирующие в Интернете, способны воздействовать не только на сознание, но и на менталитет личности. В этом случае Интернет являет собой мощный инструмент в политической борьбе противоборствующих политических сил, стремящихся к увеличению численности своих сторонников через социальные сети. Это лишний раз подчеркивает необходимость целенаправленной государственной политики в Глобальной сети, учитывающей новые закономерности политических коммуникаций, которые обеспечат внедрение новых технологий обеспечения политической деятельности, политического имиджа, избирательных кампаний, политического консалтинга [Зазыкин, Кирсанов, Пирогов 2019: 10-89, 132-216].

Во многих исследованиях этим вопросам уделяется особое внимание [Андрианов 2002; Полякова 2015; Соловьева 2011]. В частности, отмечается, что необходим целый комплекс мер, касающихся:

a) совершенствования (как минимум, оптимизации) структуры и содержания функционирования политико-правовых механизмов регулирования отношений в глобальной сети Интернет, направленных в первую очередь на защиту индивидуальной политической безопасности от внешних негативных воздействий;

б) разработки в рамках концепции информационной безопасности ее политической составляющей как в отношении общества, так и в отношении личности;

в) создания условий для гуманистически направленной политической социализации молодежи в сети Интернет;

г) осушествления контроля деятельности в сети политических оппозиционных и экстремистских групп и блокирования их интернет-контента в случаях осуществления политико-информационной агрессии против государства, общества и личности, а также нарушения общепринятых правовых и нравственных принципов политического противоборства и др.

Вернемся к исходной мысли: если сегодня российское государство является объектом политико-информационного воздействия, это означает, что такое воздействие распространяется в первую очередь на всех членов общества в целях изменения их идеологических установок. Необходимо так воздействовать на общественное мнение, чтобы искомая цель нашла поддержку в сознании каждого. Не случайно политическое противоборство всегда сопровождается массированным информационно-пропагандистским политико-психологическим воздействием на сознание людей. Так, действия США в Афганистане после событий 11 сентября 2001 г., стран НАТО в бывшей Югославии изначально предусматривали мощную информационную поддержку. Впоследствии для освещения проводимых военных операций американскими специалистами по компьютерным технологиям (или с их помощью) только в Интернете было создано огромное число таких сайтов. Аналогичным образом происходило информационное обеспечение операций в Косово, когда только за первые полмесяца военных действий агентство $C N N$ выплеснуло в обычных средствах массовой информации более 30 специально подготовленных публикаций с активным использованием в текстах таких выражений, как «этнические чистки», «беженцы», «массовые политические убийства» и т.п., а затем раз- 
местило их в сети Интернет. Такая тактика массированного информационного воздействия применялась в Ираке, Ливии, Тунисе, Сирии, Украине, Молдове и других странах, в т.ч. и в России [Маруев 2010; Манойло, Петренко, Фролов 2003]. Благодатная почва для этого всегда существует в любой стране - где-то в меньшем объеме, где-то в большем. Все зависит от того, насколько сильны в сознании людей ментальные и ценностно-мировоззренческие основы, обеспечивающие иммунитет ко всем конфликтно-проблемным угрозам, и каковы возможности воздействия различных информационных факторов на протекающие в обществе социально-политические процессы. Важно также учитывать, насколько гармонизированы при этом политические интересы личности с политикой государства, трансформации общественного миропонимания - с парадигмами личностного самоопределения, чтобы не происходило расщепление и дифференциация совокупного политического интереса общества. Свою весьма значительную роль в этом должна сыграть информационная культура личности, концентрирующая в себе результаты личностных, общественных и государственных усилий в решении проблем безопасности.

Поясним эту мысль. Информационное общество объективно создает противоречия для различных социальных групп, поскольку их информационная культура формируется в разных условиях: у одних этот процесс идет под непосредственным воздействием новых информационных и телекоммуникационных технологий, широкого доступа к социальным сетям, у других такие возможности ограничены, и их информационная культура предопределена традиционными средствами коммуникации. Здесь следует обратить внимание на один весьма важный факт: саморазвитие, безусловно, есть необходимый элемент формирования информационной культуры, но очень важно, чтобы этот процесс не ограничивался рамками информационной культуры, развивая в личности «одномерность» (Г. Маркузе) и стимулируя рационализм мышления и поведения. Как отмечает академик В.А. Лекторский, «развитие технической рациональности в самом широком смысле (включая технику ведения экономических, административных, политических и иных дел) не только не привело к росту человеческой свободы, а наоборот, выразилось в создании системы механизмов, имеющих собственную логику функционирования, отчужденных от человека и противостоящих ему и его свободе» [Лекторский 2001: 86]. Рационализм в сознании и деятельности приводит к тому, что личность ассоциирует себя главным образом с информационным полем, что таит в себе опасность утраты индивидуальности и понижения уровня общекультурного развития, что крайне нежелательно для обеспечения ее политической безопасности.

Подведем итоги. Информационное общество перемещает человека в искусственно созданную им же информационную среду, которая начинает предъявлять к нему свои собственные требования во всех сферах жизнедеятельности, в т.ч. в сфере политических отношений. В этих условиях во весь рост встает проблема формирования информационной культуры личности, которая уже в ближайшем будущем может стать доминирующей в структуре общей культуры. Ее роль особенно четко проявляется сегодня в гуманитарной области, более всего связанной с обеспечением политической безопасности личности, поскольку информация и знания предопределяют степень общей безопасности в целом.

Стержнем информационной культуры как многоуровневой системы информационных взаимодействий в информационном обществе является новое информационное мировоззрение, преломленное для каждой сферы деятельности человека. Нескончаемый поток обрушивающейся на личность 
политической информации обусловливает эффект «информационно-политической перегрузки», негативно сказывающейся на ее (личности) политической безопасности: необходима «информационная отфильтровка» и достаточный уровень информационной культуры, чтобы обеспечить необходимую ее защиту.

Информационная культура - необходимый компонент общей адаптации личности к условиям политической жизни в информационном обществе. Процесс ее политической социализации следует рассматривать в единстве с обеспечением политической безопасности, поскольку современные средства массовой информации и коммуникации, глобальная сеть Интернет представляют свои «заготовки» оценки политической реальности, далеко не всегда соответствующие политическим интересам, мировоззренческим позициям и ценностям каждого отдельного человека и общества в целом. В формировании информационной культуры как стратегического ресурса политической безопасности личности в информационном обществе решающая роль отводится мотивации человека к непрерывному образованию в течение всей жизни.

\section{Список литературы}

Андреева Г.М. 2000. Психология социального познания. М.: Аспект Пресс. 288 с.

Андрианов Д.А. 2002. Политическая компонента информационной безопасности российского общества: автореф. дис. ... к.полит.н. М. 24 с.

Вачнадзе Г.Н. 1989. Всемирное телевидение. Новые средства массовой информации - их аудитория, техника, бизнес, политика. Тбилиси: Ганатлеба. 672 с.

Давыдов С.Г. 2000. Сетевая массовая коммуникация как социальное явление: социально-философский анализ: автореф. дис. ... к.филос.н. М. 24 с.

Зазыкин В.Г., Кирсанов А.И., Пирогов А.И. 2019. Технологические ресурсы политической деятельности: учебное пособие. М.: Ваш Формат. 261 с.

Иванов В.Е. 2000. Интернет в формировании диалогического пространства в социокультурной среде. - Мир психологии. № 2. С. 52-56.

Кирсанов А.И. 2007. Научная политика в условиях глобализации. М.: МГАДА. $191 \mathrm{c}$.

Лекторский В. А. 2001. Эпистемология классическая и неклассическая. М.: Эдиториал УРСС. 256 с.

Манойло А., Петренко А., Фролов Д. 2003. Государственная информационная политика в условиях информационно-психологической войны. М.: Горячая линия - Телеком. 543 с.

Маруев А.Ю. 2010. Информационная безопасность России и основы организации информационного противоборства. - Проблемный анализ и государственно-управленческое проектирование. Вып. 1. С. 47-54.

Нурмеева Н.Р. 2008. Формирование информационной культуры как отражение современных требований информационного общества. - Образовательные технологии и общество. Т. 11. № 4. С. 406-409.

Петрова Е.В. 2010. Проблема адаптации в информационной среде. Информационная эпоха: вызовы человеку. М.: РОССПЭН. С. 258-281.

Пирогов А.И. 1995. Информатизация как объективная закономерность развития современного общества. М.: Изд-во Военного университета. $123 \mathrm{c.}$

Полякова Г.В. 2015. Информационная культура в современном обществе: философские аспекты: автореф. дис. ... к.филос.н. М. 27 с.

Соловьева Е.А. 2011. Информационное противоборство в сети Интернет: политологический анализ: автореф. дис. ... к.полит.н. Пятигорск. 23 с.

Тоффлер Э. 2002. Шок будущего. М.: АСТ. 557 с. 
Хакен Г. 1991. Информация и самоорганизация: макроскопический подход к сложным системам. М.: Мир. 240 с.

Чернов Г.Ю. 2011. Концепт демассификации: многообразие подходов.

- Вестник Челябинского государственного университета. Сер. Философия. Социология. Культурология. № 30. С. 141-148.

\section{INFORMATION CULTURE AS A STRATEGIC RESOURCE FOR POLITICAL SECURITY OF PERSONALITY IN THE INFORMATION SOCIETY}

Abstract. The article considers some problems of political security of personality in a modern information society and the
role of information culture in this issue. The author characterizes the content of information culture as well as the role of
education, mass media and communication and the Internet in ensuring the political security of an individual.
Keywords: information, information culture, information society, political security, personality, state, mass media, Internet

УДК 316.4

АТЛАСКИРОВ Альберт Русланович - кандидат социологических наук, старший научный сотрудник иентра социально-политических исследований Кабардино-Балкарского научного центра РАН (360002, Россия, Кабардино-Балкарская Республика, г. Нальчик, ул. Балкарова, 2; atlaskirov.albert@ yandex.ru)

\section{ВИРТУАЛЬНЫЙ ИГРОВОЙ МИР: ДЕМОКРАТИЯ, АВТОРИТАРИЗМ И РЕВОЛЮЦИИ}

Аннотация. В эпоху постмодернизма виртуальные игры перестали быть забавой молодежи. В современных играх создаются вселенные, участниками которых являются и люди среднего поколения, у которых есть работа, семья, дети. Если для молодежи виртуальный игровой мир - это пространство сиюминутных развлечений, то чем же руководствуются зрелые и состоявшиеся в реальной жизни люди? Целью статьи является исследование особенностей взаимодействия людей в виртуальном игровом мире. Полем исследования выбрана одна из наиболее популярных в мире игр в жанре экшн-стратегий - Dawn of Titans. Игра была выбрана исходя из того, что данный жанр (стратегии) формирует более крепкие и долгосрочные взаимоотношения среди участников и в меньшей степени подвержен фрагментации, нестабильности социальных связей.

Ключевые слова: виртуальная игра, демократия, авторитаризм, социальная мобильность, социальное расслоение, молодежь, эскапизм

Актуальность. С каждым годом увеличивается число людей, для которых виртуальный мир игр из мимолетного развлечения, способа проведения досуга превращается в неотъемлемую часть жизни, гармонично взаимодействующую с реальностью. В наиболее развитых странах мира (Япония, Южная Корея, 